16 a 18 de outubro de 2019 - Campinas | Brasil

\title{
A violência no cotidiano das pessoas transgêneras: revisão integrativa
}

\section{Dalvani Marques, Leonardo J. Correia Rocha*, Nathalia F. S. Tosti, Nubya S. Anzolin.}

\section{Resumo}

Objetivo: analisar a produção científica sobre a temática da violência contra pessoas transgêneras a fim de identificar e analisar os tipos de violência que acometem essa população e suas formas de manifestação no cotidiano. Método: revisão integrativa de artigos com amostra incluindo quatorze artigos nacionais e internacionais, em inglês, português e espanhol, das bases de dados PubMed e BIREME. Resultados: das oito tipologias de violência encontradas a violência verbal, física e sexual são mais prevalentes nos artigos. As características de manifestação no cotidiano são discutidas em quatro categorias que levam em conta os agentes e locais de ocorrência. Conclusão: mesmo em diferentes contextos, os processos de violência possuem a mesma matriz motivadora que é o estigma social contra as pessoas trans. As consequências para o processo saúde-doença dessa população e os relatos de dificuldade no acesso aos serviços de saúde, evidenciam a necessidade da real inclusão dessa população sob o viés da saúde.

\section{Palavras-chave:}

\section{Violência, Pessoas Transgênero, Transexualidade}

\section{Introdução}

Quando analisamos a temática da violência sob o olhar das minorias sociais, observamos que estas possuem especificidades quanto às formas de manifestação da violência. No Brasil, segundo o último Relatório Sobre Mortes Violentas de LGBT+ de 2018 do Grupo Gay da Bahia (GGB), ocorreram 420 mortes de pessoas LGBTs no país, dentre estes ,164 Transgêneros (Trans) (39\%). Dito isso, é tido como objetivo deste estudo analisar a produção científica sobre a temática da violência contra pessoas transgêneras a fim de identificar e analisar os tipos de violência que acometem essa população e suas formas de manifestação no cotidiano.

\section{Resultados e Discussão}

A pesquisa foi realizada nas bases de dados Public MEDLINE (PubMed) e no Portal Regional da Biblioteca Virtual em Saúde (BIREME) de janeiro a maio de 2019. Utilizaram-se os descritores da MeSH (Medical Subject Headings): (1) "Violence", (2) "Transgender Persons", (3) "Transvestism" e (4) Transexualism, combinandoos pelo uso dos booleanos "and" e "or". Foram selecionados somente os artigos completos, disponíveis, publicados durante os últimos 10 anos, em inglês, espanhol ou português.

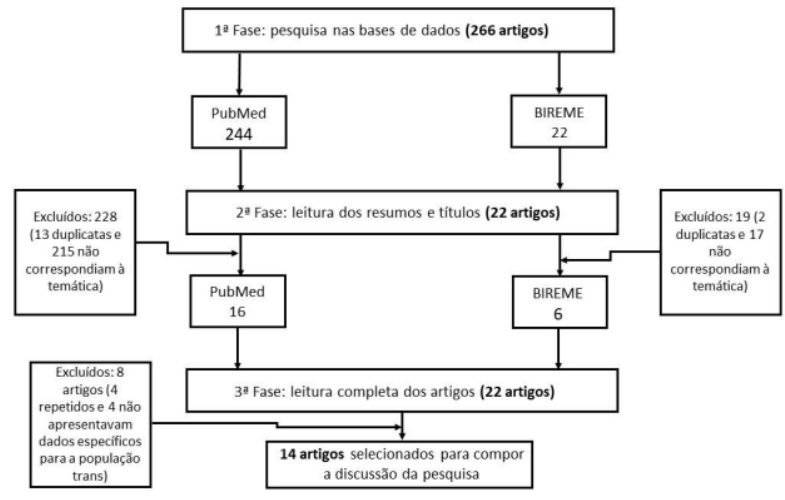

Figura 1. Representação em fluxograma da pesquisa realizada nas bases de dados, 2019.
Tabela 1. Distribuição dos tipos de violência citados nos artigos

\begin{tabular}{ccc}
\hline Tipos de violência & Artigos & Total \\
\hline Física & $(15),(16),(17),(18),(20),(21),(22),(23),(24),(25),(26),(27)$ & 12 \\
Verbal & $(15),(16),(17),(18),(19),(20),(23),(24),(25),(26),(27),(28)$ & 12 \\
Por intervenção legal (policial) & $(16)_{1}(17),(20),(23),(24),(25),(26),(27),(28)$ & 9 \\
Sexual & $(15),(17),(19),(21),(22),(23),(24),(25),(27)$ & 9 \\
Moral & $(15),(17),(19),(20),(24),(27),(28)$ & 7 \\
Fatal (familiar) & $(16),(17),(20),(24),(27),(28)$ & 6 \\
Psicológica & $(15),(17),(19),(21)$ & 4 \\
Negligência & $(15),(16),(28)$ & 3 \\
Financeira & $(17),(19)$ & 2 \\
& & \\
\hline
\end{tabular}

A violência que vem de casa: os estudos demonstram uma alta incidência de violência proferida pelos próprios membros da família das pessoas trans, vivenciando situações de agressões físicas, maus-tratos e expulsões forçadas de casa.

A violência que ronda nas ruas: a violência policial é marcada por agressões físicas e sexuais, estando mais presente no cotidiano dos indivíduos travestis, que possuem ligação com o trabalho sexual.

A violência que impacta na saúde: os estudos demonstram uma alta prevalência de doenças psicológicas e agravamento de sintomas na população trans. Ademais, demonstram que o fato da recusa em se utilizar o nome social pelos profissionais da saúde é o principal fator de evasão dos serviços de saúde.

A violência que nunca para: a violência contra pessoas trans é constante em seu cotidiano e ocorre em diversos espaços públicos e privativos.

\section{Conclusões}

Entender os mecanismos de atuação da violência no processo de saúde e doença dessas pessoas nos concede subsídios para a atuação direta nas suas demandas de saúde garantindo o alinhamento com os princípios doutrinários do SUS, como também com as diretrizes internacionais de inclusão das minorias sociais.

Butler, J. Problemas de Gênero: feminismo e subversão da identidade. Rio de Janeiro: Civilização Brasileir; 2008.

Carmo ME, GuizardiFL. O conceito de vulnerabilidade e seus sentidos para as políticas públicas de saúde e assistência social. Cadernos de SaúdePública. 2018 [cited2018 may18];34(3):e00101417. doi: 10.1590/0102-311X00101417. 